Les ANNALES Les Annales de droit

DE DROIT

11 | 2017

Varia

\title{
Continuer à tourner les pages
}

\section{Christophe Otero}

\section{OpenEdition}

Journals

Édition électronique

URL : http://journals.openedition.org/add/484

DOI : $10.4000 /$ add.484

ISSN : 2606-1988

\section{Éditeur}

Presses universitaires de Rouen et du Havre

\section{Édition imprimée}

Date de publication : 16 octobre 2017

Pagination : 07-08

ISBN : 979-10-240-0775-5

ISSN : 1955-0855

\section{Référence électronique}

Christophe Otero, «Continuer à tourner les pages », Les Annales de droit [En ligne], 11 | 2017, mis en ligne le 16 octobre 2018, consulté le 23 septembre 2020. URL : http://journals.openedition.org/add/ 484 ; DOI : https://doi.org/10.4000/add.484 


\section{Éditorial \\ Continuer à tourner les pages}

Les années passent, les Annales de droit demeurent. Notre projet reste le même tant sur le fond que sur la forme.

Sur le fond, proposer une revue originale et à nulle autre pareille, c'està-dire un support pluridisciplinaire consacré aux différentes branches de la science politique et du droit - national, européen et international - et à leurs diverses ramifications - historiques, publiques et privées. Il s'agit de la sorte de susciter l'intérêt du lecteur et de soumettre à la sagacité de celui-ci des contributions variées aux fins de découvrir ou de redécouvrir d'autres horizons. Sur ce point, le projet scientifique et la ligne éditoriale perdurent comme en attestent les sommaires des dix premiers numéros et de celui-ci où se mêlent et s'entremêlent des articles dont le point commun, volontairement recherché, est la seule rigueur de l'analyse.

Sur la forme, à l'heure de la dématérialisation et de la multiplication des supports numériques, les Annales de droit entendent se maintenir comme une revue publiée. Les membres du comité de rédaction - avec l'aide précieuse de l'évaluation des membres du comité scientifique savent combien il est agréable de voir des fichiers se transformer peu à peu en un exemplaire papier. Les auteurs connaissent cette sensation, assimilable à La Première Gorgée de bière et autres plaisirs minuscules de Philippe Delerm, l'ivresse de pouvoir tourner les pages d'une contribution patiemment distillée à partir de quelques balbutiements d'idées. Aussi, afin que demeure cette ivresse, et parce que nous tenons aussi au flacon, nous avons fait le choix de rester livresque. À ce titre, et avec ce onzième numéro, nous n'entendons pas tourner la page, mais, bien au contraire, continuer à tourner les pages. Comme les autres, une fois le numéro publié, sur le métier nous remettons, avec une certaine joie, une once de fierté et beaucoup d'humilité, l'ouvrage... papier.

Christophe Otero pour le comité de rédaction 